\title{
An interesting case of Phocomelia
}

\section{Lavanya ${ }^{1 *}$, T. Ramani Devi², D. Gayathri ${ }^{3}$}

\author{
${ }^{1}$ Department of Obstetrics and Gynecology, Malar hospital, Trichy, Tamil Nadu, India \\ ${ }^{2}$ Department of Obstetrics and Gynecology, Ramakrishna Medical Centre LLP and Janani Fertility Centre, Trichy, \\ Tamil Nadu, India \\ ${ }^{3}$ Department of Obstetrics and Gynecology, Ramakrishna Medical Centre LLP, Trichy, Tamil Nadu, India
}

Received: 25 September 2019

Revised: 21 December 2019

Accepted: 27 December 2019

\author{
*Correspondence: \\ Dr. C. Lavanya, \\ E-mail:drlavs@hotmail.com
}

Copyright: ( ) the author(s), publisher and licensee Medip Academy. This is an open-access article distributed under the terms of the Creative Commons Attribution Non-Commercial License, which permits unrestricted non-commercial use, distribution, and reproduction in any medium, provided the original work is properly cited.

\begin{abstract}
Authors present a very rare case of tetra-phocomelia evaluated by antenatal ultrasonography. It is a condition seen in 0.62 per 100,000 live births. This is a congenital chromosomal abnormality involving the musculoskeletal system. Primi gravida with spontaneous conception after a long period of infertility underwent early anomaly scan. Patient was not aware of the last menstrual period hence; NT scan was missed. Routine early anomaly scan done between 1618 weeks of pregnancy diagnosed a fetus with Tetra-Phocomelia. Due to the lack of associated symptoms or significant history, our case did not fit into any specific syndrome and appears to be the result of a sporadic, nonhereditary limb deficiency involving all four limb buds. Second opinion obtained from a fetal medicine consultant who confirmed the diagnosis. Hence, decided for mid trimester termination and fetus was expelled after 8 hours. Fetus was not sent for pathological analysis. Tetra-phocomelia is a rare congenital anomaly and it may be associated with other deformity also. $1^{\text {st }}$ case of phocomelia was described after the intake of thalidomide. In this condition hands and feet are seen as small flippers of a seal. The differential diagnosis includes sporadic phocomelia, HoltOram syndrome, thrombocytopenia-absent radius syndrome (TAR syndrome), Robert's syndrome, and thalidomideinduced phocomelia. Here authors are presenting a rare case of Phocomelia where there is no history of drug intake or family history. This has to differentiate from thrombocytopenia-absent radius syndrome (TAR syndrome), sporadic phocomelia, Holt-Oram syndrome, Robert's syndrome, and thalidomide-induced phocomelia.
\end{abstract}

Keywords: Early anomaly scan, Flippers, Limbs, Tetra-phocomelia, Thalidomide

\section{INTRODUCTION}

Tetra-phocomelia is a rare congenital anomaly involving the musculoskeletal system. There is symmetrical limb reduction in utero, mostly humerus or femur, radius or tibia, ulna or fibula. It may be totally absent or markedly hypoplastic, with foot or hand attached to the trunk of the fetus. Number of the toes or fingers may vary in number.

Phocomelia is a Greek terminology which refers to the similarity of patient's limb to the flippers on a seal. In some of the syndromic (Multisystem) phocomelias, gene mutation on different chromosome has been found and this disorder is described at autosomal recessive. ${ }^{1,2}$ Phocomelia is a defect known to be produced by thalidomide. Though the causes for most of the cases of phocomelia are not clearly understood. Left side upper limbs are the commonest site of phocomelia. The defect is unilateral more than bilateral.

In 1996 Castilla et al, reported 34 cases of phocomelia due to thalidomide exposure have been reported in Brazil 
where the drug has been used in treatment of leprosy. The sensitive period for phocomelia were between days 24 and 33 after fertilization for the involvement of upper limb and between days 28 and 33 for lower limb involvement. ${ }^{3}$ The incidence of phocomelia varies from 0.6 per 100,000 live births to 4.2 per 100,000 live births thorough out the world. But the incidence of true phocomelia is not understood. ${ }^{4}$

\section{CASE REPORT}

A 26 years old primi gravida conceived spontaneously after 4 years of infertility treatment. Patient was unaware of her pregnancy due to irregular cycles. Hence, dating scan and NT scan was missed. She consulted at 16 weeks and hence she was subjected to early anomaly scan. As there was suspicion of limb anomalies detailed evaluation by a fetal medicine consultant was obtained.

\section{History}

- There was no history of consanguinity

- Menstrual cycles were irregular

- There was no significant medical or surgical history

- She had taken few cycles of ovulation induction drug

- No h/o drug intake or radiation exposure

- No family history of anomalous fetus.

\section{USG}

- The fetus showed micrognathia and normal nasal bone

- There was deviation of cardiac axis to the extreme left and VSD was noted

- Both lungs normal

- Stomach bubble not imaged and both kidneys and bladder were normal

- Rudimentary stump noted in the region of upper and lower limbs

- Fetal brain was normal and spine normal.

These USG findings were suggestive of tetro phocomelia (Figure 1-4).

After discussing the anomaly with the parents, termination of the pregnancy was decided. Labour was induced with mifeprine $600 \mathrm{mg}$ orally and misoprostol $400 \mathrm{mcg}$ vaginally (48 hours later). The patient expelled dead fetus after 8 hours of misoprostol. The fetus showed typical seal like flippers of the upper limbs and the lower limbs. Hence the diagnosis of tetra phocomelia was confirmed. In view of tetramelia with facial dysmorphism and cardiac disorder provisional diagnosis of Robert's Syndrome was made. Fetal karyotyping, gene sequencing and post mortem couldn't be done as the parents were not willing (Figure 5).

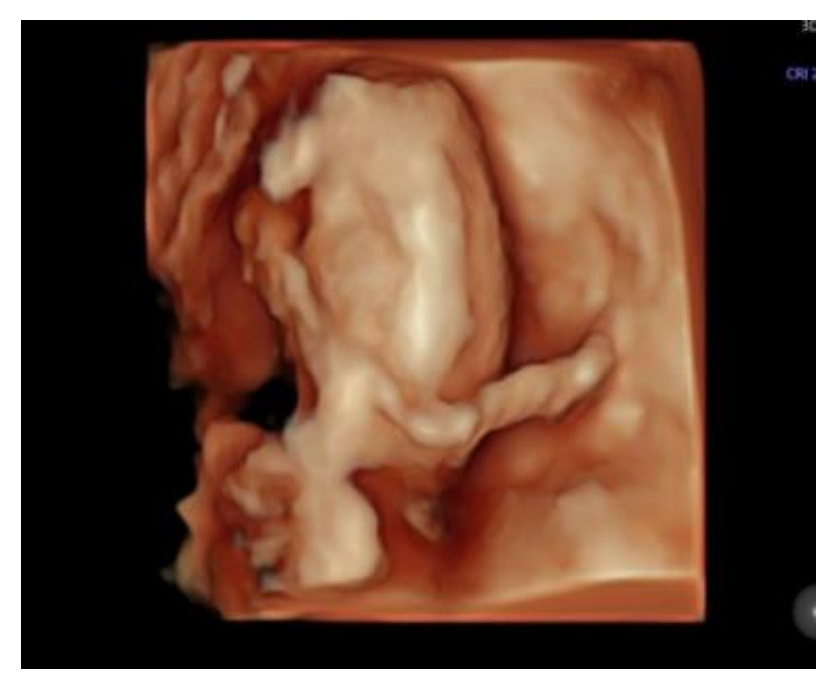

Figure 1: Spine.

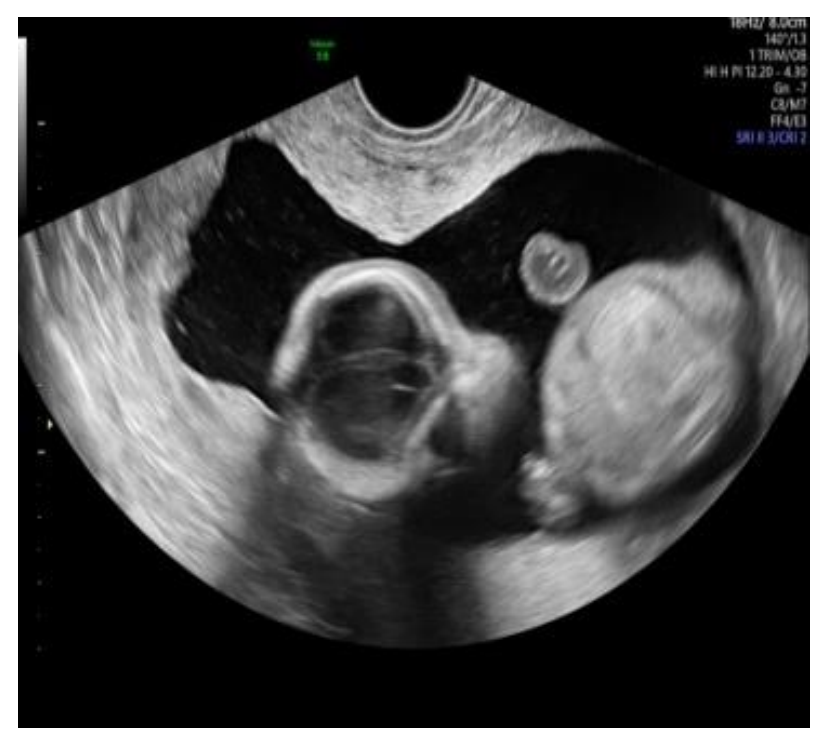

Figure 2: Upper limbs.

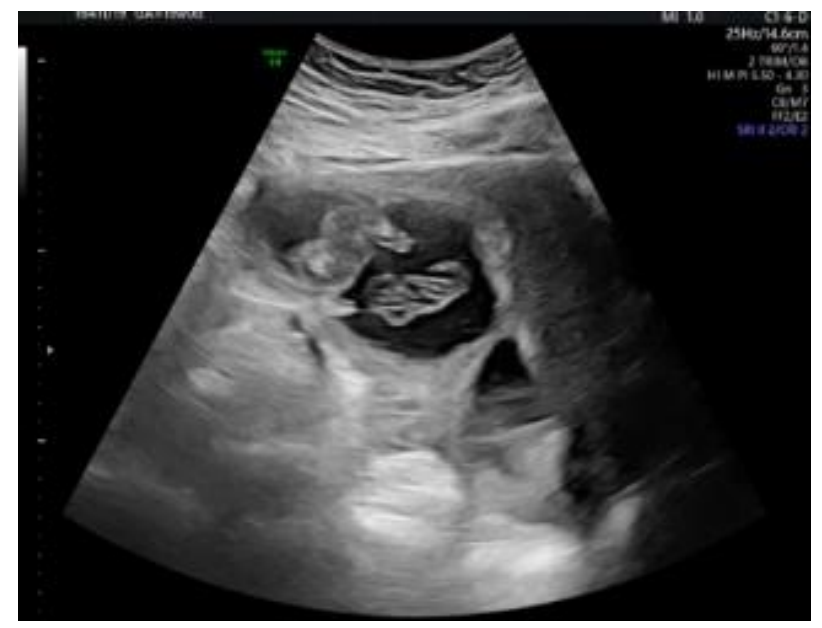

Figure 3: Lower limbs. 


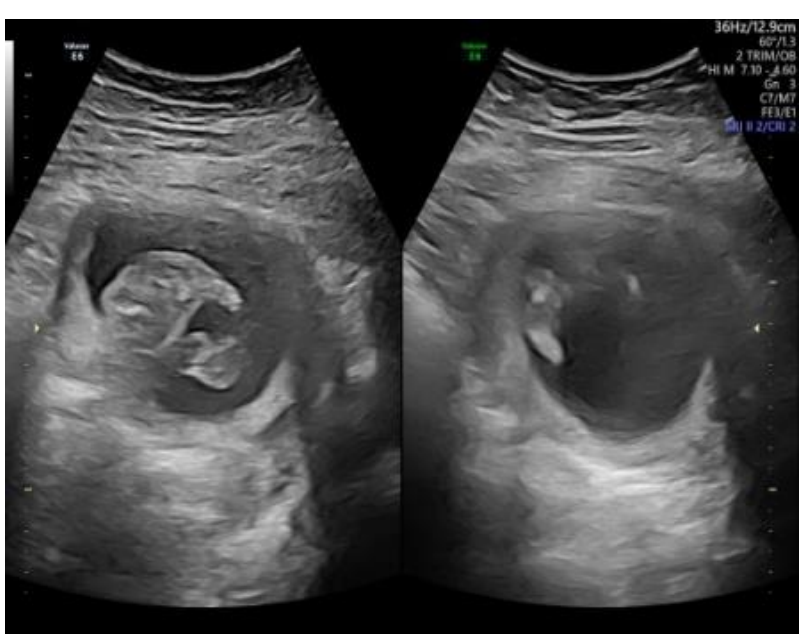

Figure 4: Lower limbs.

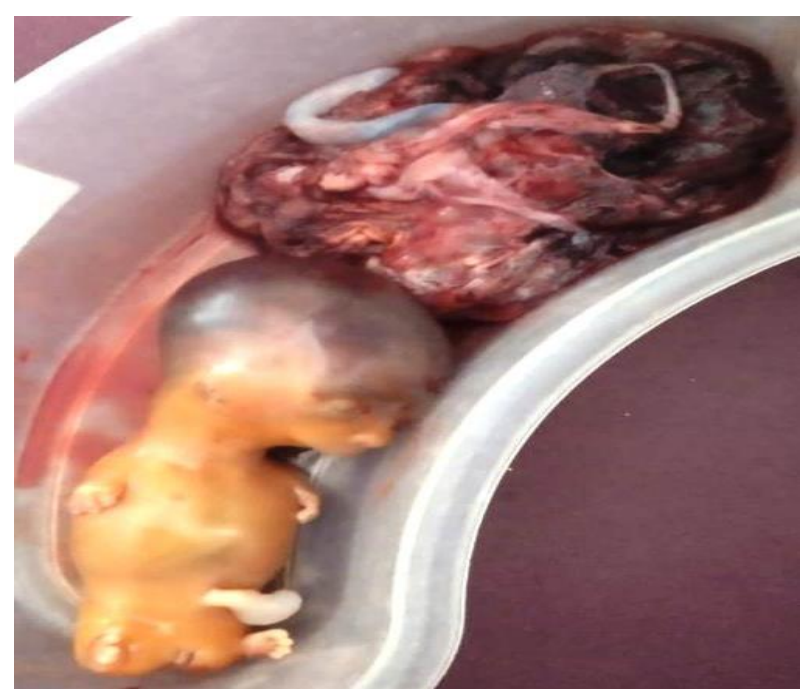

Figure 5: Specimen of the fetus and placenta.

\section{DISCUSSION}

Phocomelia is a rare congenital malformation where there is absence of the limbs and may be associated with various other deformities. Meromelia is a condition where there is partial absence of limbs and in Amelia one arm or leg is absent. This term was coined by Etienne Geoffroy Saint Hilaire 1836. The first case of phocomelia was reported in Germany born to a mother who had taken Thalidomide. When all the four limbs are affected it is known as "tetra-phocomelia". It's an ancient Greek word. "tetra" = four, "phoco" = seal and "melos" = limb. Here in this deformity hands and feet arise as small appendages from shoulder or pelvis like the flippers of a seal.

According to National Organization of Rare Disorders (NORD) this is an inherited autosomal recessive trait where the malformation is associated with chromosome 8.

The true phocomelia is seen in only 0.62 per 100,000 births. Various attributing causes include intake of drugs, substance abuse, radiation, diabetes, genetic etc. in pregnancy.

Phocomelia was further sub classified into AlAwadi/Raas-Rothschild syndrome (AARR syndrome), Robert's / SC phocomelia, Schinzel phocomelia and Zimmer phocomelia (Table 1).

The differential diagnosis includes Thrombocytopeniaabsent radius syndrome (TAR syndrome), Robert's syndrome, Holt-Oram syndrome, thalidomide-induced phocomelia and sporadic phocomelia.Thrombocytopeniaabsent radius syndrome (TAR) is a genetic disorder characterized by lack of radial bone in the fore arm, low platelets and additional deformities like skeletal disorders of hands, arms and legs. ${ }^{5-7}$ Cardiac abnormalities, micrognathia and low set ears. TAR syndrome should be excluded in this particular patient.

Robert's syndrome is a rare autosomal recessive genetic disorder which includes mental retardation, growth retardation with prenatal onset and continuing postnatal tetra hypomelia which is prominent more in the upper extremities, mid line cranio facial abnormalities. ${ }^{8,9}$ Cardiac abnormalities are noted in $50 \%$ of cases.

Table 1:Different types of phocomelia and clinical features seen in our case. ${ }^{4}$

\begin{tabular}{|c|c|c|c|c|c|}
\hline & $\begin{array}{l}\text { Our } \\
\text { patient }\end{array}$ & $\begin{array}{l}\text { AARR* } \\
\text { syndrome }\end{array}$ & $\begin{array}{l}\text { Zimmer } \\
\text { phocomelia }\end{array}$ & $\begin{array}{l}\text { Schinzel } \\
\text { phocomelia }\end{array}$ & $\begin{array}{l}\text { Robert's SC } \\
\text { phocomelia }\end{array}$ \\
\hline Limb deficiency & + & + & \pm & + & + \\
\hline Skull deficiency & - & - & + & + & + \\
\hline Pelvic aplasia/hypoplasia & - & + & + & + & - \\
\hline Uterine agenesis & - & - & + & \pm & - \\
\hline Cryptorchidism & - (Female) & \pm & \pm & \pm & + \\
\hline Renal anomaly & - & + & - & + & - \\
\hline Oral cleft & - & + & + & \pm & + \\
\hline $\begin{array}{l}\text { Abnormal facial features (including } \\
\text { ear, nose and chin) }\end{array}$ & + & + & + & - & + \\
\hline
\end{tabular}

*AARR Syndrome: Al-Awadi/ Raas-Rothschild Syndrome. 
Holt-Oram syndrome may be seen both as an autosomal dominant disorder and as result of spontaneous genetic mutations. $^{10,11}$ This syndrome is characterized by abnormal limb development that affects mostly the forearm and the carpal bones of the wrists. Characteristic features include a hypoplastic thumb or a thumb that looks like a finger. Frequently, the radius will be missing and the humerus is underdeveloped. The clavicle and scapula may be affected. Three-quarters of the patients with Holt-Oram syndrome have cardiac problems that may include atrial septal defects or ventricular septal defects. They usually don't have lower limb involvement so it can be excluded in this patient.

Thalidomide-induced phocomelia. ${ }^{12,13}$ This drug was first introduced in 1957 in West Germany for anxiety, insomnia, and gastritis. Later, this medication was used for nausea and morning sickness in the early stages of pregnancy. The drug was available over-the-counter in 1960, and shortly thereafter, 5,000 to 7,000 infants were born with signs of phocomelia. Other abnormalities included eye deformities, blindness, deafness, and abnormalities of the cardiac, gastrointestinal, genitourinary, and nervous systems. Thalidomide has anti- inflammatory and anti- angiogenic actions. The S isomer is responsible for the teratogenic actions. Thalidomide is known to block the angiogenesis in the chick limb and induced cell death and formation of ROS. It blocks the growth factors signaling the proximal limb development and allows the distal limb bud development leading to phocomelia. Still the exact mechanism phocomelia is unclear.

The drug was withdrawn from western markets in 1962. After 1965, the drug was remarketed in several countries for the treatment of erythema nodosum leprosum. Hence there was an outbreak of phocomelia in Brazil where leprosy patients were treated with thalidomide. There was no history of any drug intake in our patient.

Sporadic phocomelia is a rare genetic condition which is inherited either as an autosomal recessive trait or due to spontaneous mutations. ${ }^{14}$ If parents are found to be carriers then there is $25 \%$ of chance for the child to be affected. Here history of consanguinity plays a major role in diagnosis of sporadic phocomelia.

The final diagnosis in this fetus could be sporadic phocomelia or Robert's syndrome.

Fetal ultrasound is practiced all over the world for last three-four decades. Most of the limb defects can be seen or suspected at time of nuchal translucency evaluation. These patients need follow up around 16-18 weeks to give the correct details of limb deformity. Ultrasonography should be meticulously performed and should be cautiously interpreted. Present case fulfilled all the criteria described for tetra-phocomelia.
The study regarding laterality was done by Kallen et al 1984 among 48 cases. $29 \%$ had right side and $22 \%$ had left side and $48 \%$ it was bilateral. $69 \%$ had upper limb involvement, $29 \%$ had lower limb involvements and $2 \%$ had both limbs involvements.

\section{CONCLUSION}

Based on our observations and experience, antenatal ultrasonography remains the hallmark for detecting all fetal anomalies including that of limbs. Majority of the anomalies could be detected between 12-14 weeks during NT scan. Molecular biology would aid in further evaluation and confirmation. Such cases are isolated or sporadic due to certain genetic inheritances.

This case has been presented in view of its occurrence, presentation in a low risk pregnancy.

\section{Funding: No funding sources \\ Conflict of interest: None declared \\ Ethical approval: Not required}

\section{REFERENCES}

1. Schüle B, Oviedo A, Johnston K, Pai S, Francke U. Inactivating mutations in $\mathrm{ESCO} 2$ cause $\mathrm{SC}$ phocomelia and Roberts syndrome: no phenotypegenotype correlation. Am J Human Genetics. 2005;77(6):1117-28.

2. Sharma A, Chaudhary R, Shukla A, Chaudhary UK, Sharma K, Gupta A. Nonsyndromic phocomelia: a case series. Translational Biomed. 2016;7(1).

3. Bermejo-Sánchez E, Cuevas L, Amar E, Bakker MK, Bianca S, Bianchi F, et al. Amelia: A multi-center descriptive epidemiologic study in a large dataset from the International Clearinghouse for Birth Defects Surveillance and Research, and overview of the literature. Am J Med Genetics Part C: Seminars in Medical Genetics. 2011;157(4):288-304.

4. Samal SK, Rathod S, Ghose S. Tetra-phocomelia: the seal limb deformity-a case report. J Clin Diagnos Res. 2015;9(2):QD01.

5. Asadi $\mathrm{S}$. The role of genetic mutations in gene RBM8A in thrombocytopenia-ab-sent radius syndrome. J Genet Genome Res. 2019;5:043.

6. Bonsi L, Marchionni C, Alviano F, Lanzoni G, Franchina M, Costa R, et al. Thrombocytopenia with absent radii (TAR) syndrome: from hemopoietic progenitor to mesenchymal stromal cell disease?. Experimental Hematol. 2009;37(1):1-7.

7. Greenhalgh KL, Howell RT, Bottani A, Ancliff PJ, Brunner HG, Verschuuren-Bemelmans $\mathrm{CC}$, et al. Thrombocytopenia-absent radius syndrome: a clinical genetic study. J Med Genet. 2002;39(12):876-81.

8. Sharma RK, Sharma GR, Bista P, Jha R. A child with roberts syndrome: a case report. Nepal J Neurosci. 2017;14(2):39-42. 
9. Vega H, Waisfisz Q, Gordillo M, Sakai N, Yanagihara I, Yamada M, et al. Roberts syndrome is caused by mutations in ESCO2, a human homolog of yeast ECO1 that is essential for the establishment of sister chromatid cohesion. Nature Genet. 2005;37(5):468.

10. Aviña-Fierro JA, Colonnelli-Barba G. Holt-Oram syndrome associated with facial anomalies. A case report. Revista Médica del Instituto Mexicano del Seguro Social. 2010;48(6):657-9.

11. Naik N, Rao MS, Sneha S, Reddy S. The classical holt oram syndrome. J Cardiovascular Dis Res. 2016;7(1).

12. Schuler-Faccini L, Soares RC, de Sousa AC, Maximino C, Luna E, Schwartz IV, et al. New cases of thalidomide embryopathy in Brazil. birth defects research part A. Clin Molecular Teratol. 2007;79(9):671-2.
13. Vianna FS, Lopez-Camelo JS, Leite JC, Sanseverino MT, da Graça Dutra M, Castilla EE, et al. Epidemiological surveillance of birth defects compatible with thalidomide embryopathy in Brazil. PLoS One. 2011;6(7):e21735.

14. Mousa Tia KI, Al Ghafri AA. Bilateral symmetrical distal lower limbs phocomelia, micrognathia/retrognathia, cleft palate and other congenital anomalies. J Clin Case Rep. 2018;1(1):1009.

Cite this article as: Lavanya C, Devi TR, Gayathri D. An interesting case of Phocomelia. Int J Reprod Contracept Obstet Gynecol 2020;9:866-70. 